\title{
Transfusing blood safely and appropriately
}

This Clinical review contains an incorrectly referenced statement in the second paragraph of the section "When is blood transfusion appropriate?” (BMJ 2013;347:f4303, doi:10.1136/ bmj.f4303). The last sentence, which reads "Patients with platelet counts greater than $50 \times 109 / \mathrm{L}$ or an international normalised ratio (INR) less than 2.0 can undergo invasive procedures without serious bleeding and do not need correction of these laboratory abnormalities before the procedure," has been incorrectly linked to reference 2 . In fact, this sentence should have been linked to reference 1 (National Blood Authority, Australia. Patient blood management guidelines), which refers to a series of guidelines developed in Australia and New Zealand. M F Murphy and colleagues would like to clarify that the recommendations they refer to in these guidelines are derived from consensus agreement on topics that have no randomised controlled trials to define practice, although there is mounting observational evidence supporting these recommendations.

Cite this as: BMJ 2013;347:44799

๑ BMJ Publishing Group Ltd 2013 